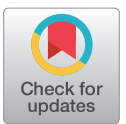

\section{Case Report}

\title{
Extending the stroke treatment window beyond DAWN in patients with very slow progressor type collaterals: How far can we go?
}

\author{
Igor Pagiola ${ }^{1,2,4}$, Olivier Chassin ${ }^{3}$, Sophie Gallas ${ }^{1}$, Mariana Sarov Riviere ${ }^{3}$, \\ Nicolas Legris ${ }^{3}$, Cristian Mihalea', Jildaz Caroff', Leon Ikka', Vanessa Chalumeau', \\ Guilherme Brasileiro de Aguiar' ${ }^{1}$, Augustin Ozanne', Jacques Moret' ${ }^{1}$, \\ Christian Denier ${ }^{3}$, Laurent Spelle ${ }^{1}$
}

\begin{abstract}
${ }^{7}$ Department of Interventional Neuroradiology Neuri Brain Vascular Center, Hopital Bicetre, APHP, Paris Sud Université, France

${ }^{2}$ Department of Interventional Neuroradiology, Hospital Estadual Central, Vitória-Espírito, Brazil ${ }^{3}$ Department of Neurology, Hopital Bicetre, APHP, Paris Sud Université, France

${ }^{4}$ Department of Neurology, Escola Superior de Ciências da Santa Casa de Misericórdia de Vitória, Hospital da Santa Casa de Vitória, Vitória ES, Brazil.
\end{abstract}

\section{$\mathrm{J}$ Cerebrovasc Endovasc Neurosurg. 2021 December;23(4):354-358 \\ Received: 28 January 2021 \\ Revised: 3 June 2021 \\ Accepted: 9 July 2021}

\author{
Correspondence to \\ Igor Pagiola \\ Department of Interventional Neurorradiology \\ Hospital Estadual Central, Rua São José, \\ 76-Parque Moscoso Vitória-Espírito Santo, \\ Brazil \\ Tel +55-27-3636-4801 \\ Fax +55-27-3636-4801 \\ E-mail igorpagiola@hotmail.com \\ ORCID http://orcid.org/0000-0001-9052-7946
}

This is an Open Access article distributed under the terms of the Creative Commons Attribution Non-Commercial License (http://creativecommons.org/licenses/ by-nc/3.0/) which permits unrestricted noncommercial use, distribution, and reproduction in any medium, provided the original work is properly cited.
Five trials published in 2015 showed the benefit of endovascular thrombectomy (ET) in patients with stroke and large vessel occlusion, extending the treatment window has become an obsession of all physicians. In 2018, the DAWN and DEFUSE-3 trials showed that, with careful selection of patients, the procedure could be carried out up to 24 hours after symptom onset with good outcomes. In addition, there have been cases where the DAWN criteria were met, and treatment occurred $>24$ hours after symptom onset. We present the case of a 68-year-old female whose groin puncture occurred 52 hours after the time last known well (TLKW), after neurological worsening of the initial situation, with a large mismatch ratio observed on magnetic resonance imaging, achieving $\mathrm{TICI}$ (the Thrombolysis in Cerebral Infarction scale) grade 3 recanalization. Five days after the procedure, the patient was discharged with NIHSS (National Institutes of Health Stroke Scale) score of 3. Some types of collateral circulation (slow progressors and "turtle" progressors, our term for very slow progressors) can extend the treatment window beyond 24 hours of the TLKW but can lead to a hyperperfusion-like syndrome immediately after the ET. Further studies are needed to evaluate the reproducibility of this hypothetical syndrome.

Keywords Cerebral blood flow, Collateral circulation, Stroke, Mechanical thrombectomy, Large vessel occlusion, Endovascular treatment 


\section{INTRODUCTION}

The treatment of stroke patients with large vessel occlusion (LVO) has completely changed after five randomized controlled trials demonstrated the superiority of endovascular thrombectomy (ET) over medical management within the first 6 hours of symptoms. ${ }^{3 / 4) 8110) 13 \text { ) }}$

The importance of extending the therapeutic window for stroke has been known since 2008. ${ }^{9)}$ In 2018, the DAWN ${ }^{11)}$ and DEFUSE- 3 trials ${ }^{2)}$ demonstrated the effectiveness of ET 6-24 hours from the time last known well (TLKW) in selected patients with mismatch between the clinical deficit severity and infarct core volume.

The type of collateral circulation in each patient can lead to either a large or small ischemic core. Patients in whom a large ischemic core is observed, have a "faster progressor" type; those with a small core have a "slow progressor" type, in which good collaterals are maintained. ${ }^{9)}$ The type of collateral circulation and consequently the rate of progression can influence the volume of ischemic core and the effectiveness of ET in patients beyond the conventional time window.

There are case series ${ }^{7}$ and case reports ${ }^{1 / 14}$ showing good outcomes in patients treated beyond the 24-hour limits of the DAWN trial.

The aim of this article is to report the case of a pa- tient who underwent ET 52 hours after the onset of symptoms, who evolved with significant neurological improvement, despite a possible hyperperfusion-like syndrome. We also conducted a brief literature review on the topic.

\section{CASE REPORT}

A 68-year-old female previously modified Rankin Scale 0 developed mild aphasia with an unknown TLKW; her daughter first observed this in the morning, while talking on the phone with the patient. Seven hours after that, the daughter visited the patient at home; the mild aphasia persisted and so they went to the hospital.

The NIHSS (National Institutes of Health Stroke Scale) score at admission was 4. Computed tomography (CT) angiography revealed a left M1 occlusion (Fig. 1). Because of the low NIHSS score and almost 7 hours after the ictus, no venous thrombolysis or interventional treatment was proposed. At that time, aspirin was prescribed.

Fifty-one hours after the TLKW, the patient had an NIHSS score of 11; a perfusion magnetic resonance imaging (MRI) revealed an ischemic core volume of $8 \mathrm{ml}$ with a large mismatch ratio observed, and therefore, an ET was proposed (Fig. 2).
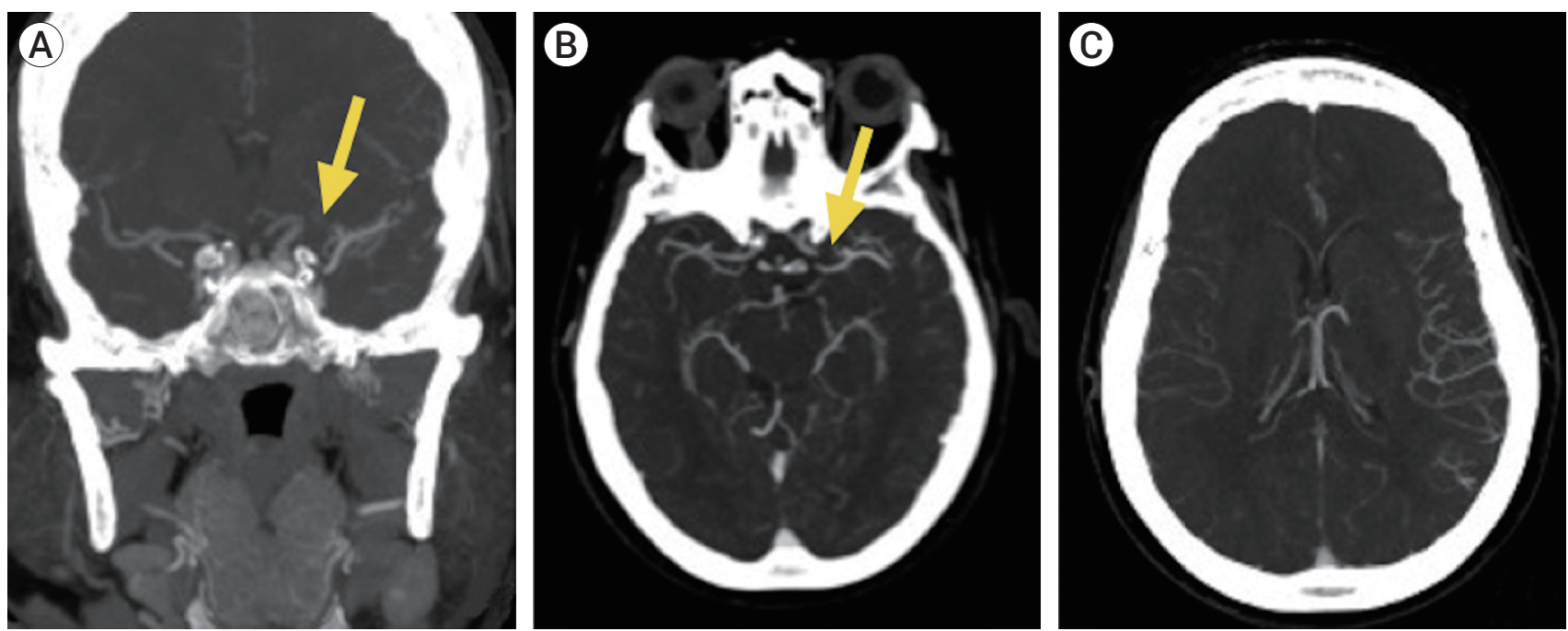

Fig. 1. Cranial CT angiography showing a left M1 occlusion (yellow arrow in A and B) with good collateral circulation to the left cerebral hemisphere (C). A-coronal view; B and C-axial view. CT, computed tomography. 

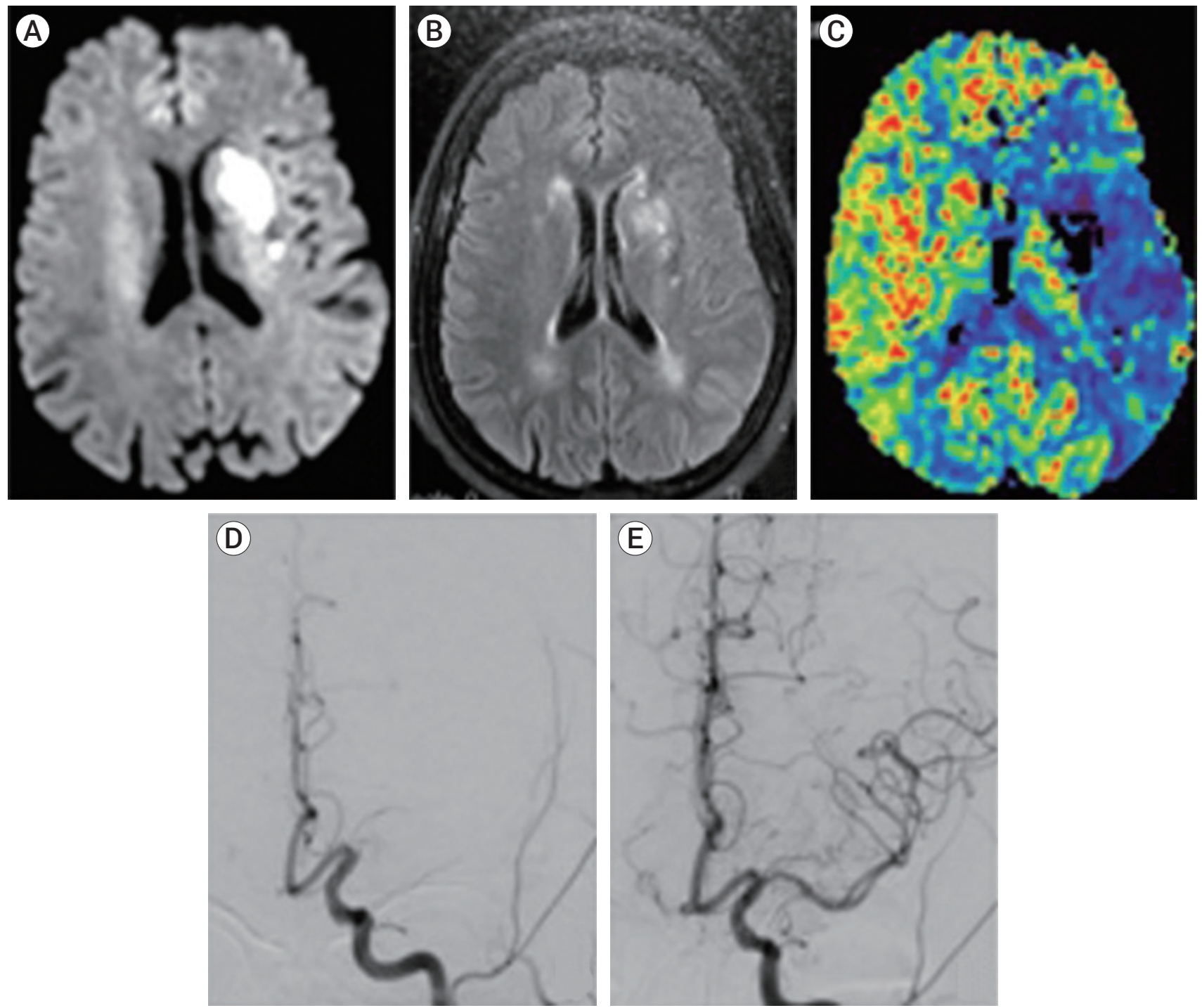

Fig. 2. MRI and perfusion MRI at 51 hours after TLKW and endovascular thrombectomy 52 hours after TLKW. MRI before endovascular treatment DWI (A), FLAIR (B) and perfusion (C), Left ICA DSA image before mechanical thrombectomy Anteriorposterior (D), and after one pass of ADAPT (E). MRI, magnetic resonance imaging; TLKW, time last known well; DWI, diffusion-weighted imaging; FLAIR, fluid-attenuated inversion recovery; ICA, internal carotid artery; DSA, digital subtraction angiography; ADAPT, a direct-aspiration first-pass technique.

Groin puncture occurred 52 hours after the TLKW; subsequently a direct-aspiration first-pass technique (ADAPT) was used and one pass resulted in a thrombolysis in cerebral infarction scale (TICI) grade 3 recanalization.

The day after the procedure, an NIHSS score of 16 was observed; no hemorrhagic signals were detected by CT.

Five days after the procedure, the patient had an NIHSS score of 3 with a mild dysarthria and partial facial palsy. She was discharged to another hospital.

The patient is followed up on an outpatient basis. In the 6-month evaluation, the patient still presents with an NIHSS score of 2, being capable of self-care (Modified Rankin Scale 2).

\section{DISCUSSION}

This kind of case raises a huge discussion about whether patients can be treated outside of the standard therapeutic window and whether the type of collateral circulation 
can extend this window. It is already known that $<30 \%{ }^{6}$ of patients with LVO have a "slow progressor" type and can benefit substantially from ET after 8 hours. This was demonstrated in the DAWN ${ }^{11)}$ and DEFUSE- $3^{2)}$ trials.

Our case presents that some patients might have a very slow progressor type, which we name "turtle" progressor type. These patients could possibly benefit from ET beyond the DAWN trial criteria ( $>24$ hours) in highly selected cases. This progressor type might exist where there is an exceptional capacity to sustain collateral blood flow, and where the ischemic core does not become enlarged, protecting the penumbra area.

Another interesting point which is seen in this case is a major worsening the day after treatment (NIHSS score of 11 to 16) without hemorrhagic transformation despite successful endovascular treatment (TICI 3). In addition to the Contrast-induced encephalopathy already described by some authors, ${ }^{5}$ it could be that patients with the slow progressor type, and in our case the "turtle" progressor type, may suffer a cerebral hyperperfusion-like syndrome when a TICI grade 3 recanalization is achieved after LVO. Because recanalization changes the low-pressure cerebral flow in the microcirculation (collateral flow) to a high-pressure flow, a hyperperfusion-like syndrome that we call "collateral syndrome" could occur. This event needs to be evaluated in other patients with the collateral profile of slow progressor and "turtle" progressor to analyze the reproducibility of this kind of "collateral syndrome".

\section{CONCLUSIONS}

This is a rare case demonstrating a very late thrombectomy 52 hours after the TLKW with a good recovery observed 5 days after the procedure.

In some cases, there appears to be a direct relationship between some types of collateral circulation (slow progressor and "turtle" progressor) and extension of the treatment window. Patients with these progressor types can experience a hyperperfusion-like syndrome ("collateral syndrome") after the recanalization of an LVO, which can lead to clinical worsening in the 48 hours immediately after the ET. However, further studies are needed in order to evaluate the reproducibility of this hypothetical syndrome.

\section{Disclosure}

The authors report no conflict of interest concerning the materials or methods used in this study or the findings specified in this paper.

\section{REFERENCES}

1. Aguilar-Salinas P, Santos R, Granja MF, Effendi S, Sauvageau E, Hanel R, et al. Revisiting the therapeutic time window dogma: successful thrombectomy 6 days after stroke onset. BMJ Case Reports. 2018;2018:bcr-2018-014039.

2. Albers GW, Marks MP, Kemp S, Christensen S, Tsai JP, Ortega-Gutierrez S, et al. Thrombectomy for stroke at 6 to 16 hours with selection by perfusion imaging. N Engl J Med. 2018 Feb;378(8):708-18.

3. Berkhemer OA, Fransen PSS, Beumer D, van den Berg LA, Lingsma HF, Yoo AJ, et al. A randomized trial of intraarterial treatment for acute ischemic stroke. N Engl J Med. 2015 Jan; 372(1):11-20.

4. Campbell BCV, Mitchell PJ, Kleinig TJ, Dewey HM, Churilov L, Yassi L, et al. Endovascular therapy for ischemic stroke with perfusion-imaging selection. N Engl J Med. 2015 Mar; 372(11):1009-18.

5. Chu YT, Lee KP, Chen CH, Sung PS, Lin YH, Lee CW, et al. Contrast-induced encephalopathy after endovascular thrombectomy for acute ischemic stroke. Stroke. 2020 Dec; 51(21): 3756-9.

6. Copen WA, Rezai Gharai L, Barak ER, Schwamm LH, Wu $\mathrm{O}$, Kamalian S, et al. Existence of the diffusion-perfusion mismatch within 24 hours after onset of acute stroke: Dependence on proximal arterial occlusion. Radiology. 2009 Mar; 250(3):878-86.

7. Desai SM, Haussen DC, Aghaebrahim A, Al-Bayati AR, Santos R, Nogueira RG, et al. Thrombectomy 24 hours after stroke: Beyond DAWN. J Neurointerv Surg. 2018 Nov; 10(11):1039-42.

8. Goyal M, Demchuk AM, Menon BK, Eesa M, Rempel JL, Thornton J, et al. Randomized assessment of rapid endovascular treatment of ischemic stroke. N Engl J Med. 2015;372: 1019-30. 
9. Hacke W, Kaste M, Bluhmki E, Brozman M, Dávalos A, Guidetti D, et al. Thrombolysis with alteplase 3 to 4.5 hours after acute ischemic stroke. N Engl J Med. 2008 Sep;359(13):1317-29.

10. Jovin TG, Chamorro A, Cobo E, Miquel MA, Molina CA, Rovira A, et al. Thrombectomy within 8 hours after symptom onset in ischemic stroke. N Engl J Med. 2015;372:2296-306.

11. Nogueira RG, Jadhav AP, Haussen DC, Bonafe A, Budzik RF, Bhuva P, et al. Thrombectomy 6 to 24 hours after stroke with a mismatch between deficit and infarct. N Engl J Med. 2018 Jan;378(1):11-21.

12. Rocha M, Jovin TG. Fast versus slow progressors of infarct growth in large vessel occlusion stroke: clinical and research implications. Stroke. 2017 Sep; 48(9):2621-7.

13. Saver JL, Goyal M, Bonafe A, Diener HC, Levy EI, Pereiraet $\mathrm{VM}$, et al. Stent-retriever thrombectomy after intravenous t-PA vs. t-PA alone in stroke. N Engl J Med. 2015 Jun; 372(24):2285-95.

14. So C, Chaudhry N, Gandhi D, Cole JW, Motta M. Endovascular thrombectomy in acute-onset ischemic stroke-beyond the standard time windows: A case report and a review of the literature. Case Rep Neurol. 2018 Sep;10(3):279-85. 